Asian Australas. J. Biosci. Biotechnol. 2020, 5 (3), 100-114

Asian-Australasian Journal of

Bioscience and Biotechnology

ISSN 2414-1283 (Print) 2414-6293 (Online)

www.ebupress.com/journal/aajbb

\title{
Article \\ Study on sustainable livelihoods of fishers from Chalan beel, Bangladesh
}

S. M. Rezaul Karim ${ }^{1 *}$, K. M. Abdul Halim ${ }^{1}$, Md. Asek Uddin $^{1}$, Most. Farida Yeasmin ${ }^{1}$, K. M. Hasanuzzaman ${ }^{1}$, Md. Nawshad Ali ${ }^{2}$ and S.M. Rahmatullah ${ }^{2}$

${ }^{1}$ Department of Fisheries, Ministry of Fisheries and Livestock, Bangladesh

${ }^{2}$ Department of Aquaculture, Bangladesh Agricultural University, Mymensingh-2202, Bangladesh

*Corresponding author: S. M. Rezaul Karim, Department of Fisheries, Ministry of Fisheries and Livestock, Bangladesh. Phone: +8801711006950; E-mail: rezaul6950@yahoo.com

Received: 06 December 2020/Accepted: 24 December 2020/ Published: 31 December 2020

\begin{abstract}
An assessment was carried out to observe the impacts of fish sanctuary on the livelihoods from fishers of Ruhul beel and Bamonji beel under Chalan beel in Pabna district of Bangladesh. Data were collected from selected sanctuary sites with prepared and pretested questionnaire and analyzed through statistical tests like ANOVA (Analysis of Variance), regression, correlation, Chi-square were used to identify the relationships between variables and significant differences/association among them. From physical capital point of view, it was found that $91.3 \%$ of fishermen's houses were katcha, $6.52 \%$ were semi-pacca, and only $2.17 \%$ were pucca in case of Ruhul beel and in case of Bamonji beel 90.54\% of fishermen's houses were katcha, 8.11\% were semi-pacca, and only $1.35 \%$ were pacca. There was no significant variation (ANOVA; P>0.05, Chi Square test; non-significant at 0.05 level) among the residences by well-being. From human capital, average age of the household heads (HHH) was 37.95( \pm ) 1.354 for Ruhul beel respectively, whereas for Bamonji beel the average age were 38.05( \pm ) 1.064. The medium aged group fishermen were dominant in Ruhul beel than Bamonji beel. There were no significant difference $(\mathrm{P}>0.05)$ found between the age groups by well-being. From income capital it was observed highest part of income were come from fishing contributing 64.89\% (653.72 \pm 128.82 US\$), $43.58 \%$ (431.89 \pm 74.66 US\$) for Ruhul beel and Bamonji beel respectively. As per as natural and social capital, average used land holding was $0.274 \pm 0.136$ ranging 0.065 ha to 0.534 ha for Ruhul beel and $0.228 \pm 0.305$ ha ranging 0.040 to 0.267 ha for Bamonji beel. The average land holdings did not vary significantly $(\mathrm{P}>0.05)$ between the sites.
\end{abstract}

Keywords: livelihood; fisher's; Chalan beel

\section{Introduction}

A livelihood comprises the capabilities, assets (including both material and social resources) and activities required for a means of living. A livelihood is sustainable when it can cope with and recover from stresses and shocks maintain or enhance its capabilities and assets, while not undermining the natural resource base. With some minor changes this is also the definition adopted by DFID (1999).

Usually about all the fishers in Bangladesh are poor, illiterate, unorganized and also neglected by the society. Almost all the fishermen live below the poverty line in our country. Their access to resources is so limited because of interfere of elite, rich and musclemen. Maximum fishers have no fishing equipment of their own. Most of them are landless and don't even have homestead land but build their houses on rivers banks or in government has land or other's lands. They rarely have to access to bank or any formal credit because of lack of their resources for giving mortgage to get the loan. Consequently, they have to depend on private moneylenders who usually charge a very high rate of interest or with the condition of selling catches in a very low and fixed price. Most of them undertake fishing on a share basis with the boat-gear owner or moneylender or as daily laborer or on a monthly salary basis by which the fishers are deprived. Through this way most of them are exploited by the middleman, money lenders, aratder, dadonder, musclemen etc. because of their low social 
status, poor, landless and disorganized (Ali et al., 2003). Although Government has given the chance to fishers for access to resources and credit but in real they don't get the chance due to lack of organizational forum for their interests and their low socio-economic status. Very recently they are getting financial, social and technological support from NGOs and other government offices like DoF, BRDB, Co-operative office etc. Livelihood Resources - the basic material and social, tangible, and intangible assets that people use for constructing their livelihoods - are conceptualized as different types of 'capital' to stress their role as a resource base 'from which different productive streams are derived from which livelihoods are constructed' (Scoones, 1998).

\section{Materials and Methods}

The study was designed to assess the impacts of fish sanctuary on the livelihoods of the fishers in Ruhul beel (RB) and Bamonji beel (BB). The major issue was the comparative analysis of different fisher's households, adoption and adaptation of integrated farming systems and assesses the institutional context in relation to their impact on livelihoods. Both qualitative and quantitative data collection methods were used in the study in an interactive way (Sayed, 2010). Data were collected at different level from the household of the selected areas based on the livelihood approach (Carney, 1998). At the initial stage of data collection, findings of Participatory Community Appraisals (PCAs) and outcomes of the research were presented and cross checked/triangulated with different levels of fishers. The research process incorporated data relating to different aspects covering the availability of the assets; the vulnerability context; transforming structures and processes including development policies, development strategies, and other related issues like agriculture practices; common livelihood strategies; and the livelihood outcomes of local people. At the beginning of the study, secondary data were collected from different sources which included books, journals, scientific publications, dissertations and bibliographies that were relevant to the study were used as useful resource to enrich the information for understanding analysis and evaluation (Karim, 2006). Information on government policy particularly on integrated aquaculture systems, current trends of aquaculture, socio-economic, environmental and institutional factors that can be considered as important to the study were gleaned from different sources.

\subsection{Phases of the study}

The study was performed in the following four phases;

\subsubsection{Phase I}

Two villages were selected from two locations of more or less similar hydrographic characteristics (sanctuary site in Ruhul beel at Patulipara village and contriol site in Bamonji beel Hatgram village) initially from Bhangura upazilla under Pabna district where the first phase of the study carried out. Before incepting the study, a meeting with key informants with the villagers was organized by the help of Upazila Fisheries Officer and then by the help of the villagers a village map was drawn.

\subsubsection{Phase II}

After finalizing the site selection questionnaire was formulated and test survey was conducted to collect data/regarding livelihood asset-base, livelihood strategies, livelihood outcomes and vulnerability context of fishing households. As 3 facilitators/enumerators were involved in data collection, variation in consistency, interpretation, unit of measures and methods of presentation of data was possible. Finally, data collection was carried out from the field level using the finalized questionnaire (Haque, 2007).

\subsubsection{Phase III}

The third step was a yearly household monitoring survey using a structured pretested questionnaire. This was conducted with the same households sampled for the survey in Step-2. The purpose of this survey carried out with fishing households was to investigate the changing patterns of livelihood systems focusing on the impacts of fish sanctuary.

\subsubsection{Phase IV}

In this Step the impact of fish sanctuary was analyzed making a comparison with the control site (BB). The main objective of the intervention was to assess the effect of change through fish sanctuary on associated livelihoods. Fishers expected to assess the effectiveness of altering fishing systems on productivity and overall livelihoods (Karim, 2006). 


\subsection{Data processing and analysis}

Initially data were entered in Microsoft Excel and exported to SPSS 20. Errors were detected and necessary corrections were made accordingly after exporting. Primary analysis (descriptive, comparative mean, graphs, Pivot tables etc.) were carried out using Microsoft Excel. Finally, quantitative and qualitative data from the study were analyzed by using SPSS/windows version 20, which offered statistical tools applied to social sciences (Field, 2005). Statistical tests like ANOVA (Analysis of Variance), regression, correlation, Chi-square were used to identify the relationships between variables and significant differences/association among them. The tools and the programs used for different type of data analysis were summarized.

\subsection{Quantitative and qualitative analysis}

Descriptive statistics such as frequency distribution, mean, standard deviation (SD), Standard error (SE), maximum, minimum, percentage, crosstabs and case summary were used for preliminary analyses. Other statistical analysis especially regression analysis, correlation coefficient, Chi-square and other as required to examine and understand the association of variables and its direction and magnitude. The statistical significance of results was estimated by using ANOVA test and t-test. ANOVA is a powerful statistical test where two or more independent estimates of the variance for the dependent variables are compared (Gay, 1976).

\subsection{ANOVA (Analysis of Variance)}

Due to heterogeneity of different sites, wellbeing, season and groups, there were many variations within the sample which were independently associated with other variables (Karim, 2006). One-way analysis of variance with post hoc analysis was used in order to identify the intra and inter group variations between different wellbeing, season (years) and locations which influenced the livelihoods, adoption, resources, production and management systems of the beels. Location, socio-economic group, farming systems and season were included as independent fixed variables.

\subsection{Pearson's chi-square test}

The chi-square test was used to find out relationship between two categorical variables (Snedecor and Cochran, 1989). Chi-square method was used to test whether two (or more) variables are: (1) independent or (2) homogeneous. The chi-square test for independence examined whether knowing the value of one variable helps to estimate the value of another variable. The chi-square test for homogeneity examines whether two populations have the same proportion of observations with a common characteristic. Though the formula is the same for both tests, the underlying logic and sampling procedures vary. Following formula used for this test where:

$$
\begin{aligned}
& X^{2}=\sum_{i=1}^{6} \frac{\left(O_{i}-E_{i}\right)^{2}}{E_{i}} \\
& O i=\text { an observed frequency } \\
& E i=\text { an expected (theoretical) frequency, asserted by the null hypothesis }
\end{aligned}
$$

\subsection{Correlation and regression analysis}

The correlation coefficient, sometimes also called the cross-correlation coefficient, is a quantity that gives the quality of a least squares fitting to the original data. The correlation coefficient is also known as the productmoment coefficient of correlation or Pearson's correlation. The main result of a correlation is called the correlation coefficient (or " $r "$ ). It ranges from -1.0 to +1.0 . The closer $r$ is to +1 or -1 , the more closely the two variables are related. Regression analysis is used to identify the linear association between independent variables used collectively to predict the dependent variables (Miles and Shevlin, 2001).

\subsection{Triangulation and validation}

The findings of the survey were shared and validated in each spot. At the end of the survey key findings were shared with participants and nonparticipants in each of two spot. At the end of presenting the results they were asked to comment and suggest if any findings were been contradictory in real. 


\section{Results}

\subsection{Physical capital}

Physical Capital is a category of livelihood assets. It comprises the basic infrastructure and physical goods that support livelihoods. The findings on physical capitals were recorded during the present study was as follows;

\subsubsection{Residence}

All the fishers lived in own house other than only one fisherman who lived in other's house in RB in both years. But in case of BB no fisherman lives in other's house. By well-being more than 50\% house owner were marginal (Table 1). There was no significant variation (ANOVA; P>0.05, Chi-Square test; non- significant at 0.05 level) in residences by well- being.

\subsubsection{Housing status}

Four types of houses were found among the fishermen in the study areas which were; 1) Katcha that were made of tin, bamboo, jute stick and trees leaves with mud floor, 2) Semi-pacca that were made of brick in one part either floor or wall but the roof was made of tin, and 3) Pucca that were made by brick eigther the wall or floor or roof. All together $91.3 \%$ of fishermen's houses were katcha, $6.52 \%$ were semi-pacca, and only $2.17 \%$ were pucca in case of RB and in case of BB $90.54 \%$ of fishermen's houses were katcha, $8.11 \%$ were semi-pacca, and only $1.35 \%$ were pacca. There was no significant variation (ANOVA; P>0.05, Chi Square test; non-significant at 0.05 level) among the residences by well-being (Table 1 ).

\subsubsection{Use of electricity}

Overall $60.87 \%$ households had no electricity connection in RB and in case of BB $77.03 \%$ house hold had electricity connection. The largest number of $\mathrm{HH}$ with electricity availability was marginal by well-being. It was found that electricity facilities were comparatively lower in RB than BB. A significant difference was found (ANOVA; $\mathrm{P}<0.001$ ) between locations (but not between years) for electricity availability $(\mathrm{F}=39.19)$ and sanitation status $(\mathrm{F}=354.83)$ (Table 1).

\subsubsection{Drinking water}

All of the fishermen had the access of clean and safe drinking water. Although, $7 \%$ and $11 \%$ fishermen from RB and BB respectively, did not have own tube-well but they used tube-well water from others (Table 1).

\subsubsection{Cooking fuel}

All the HH use straw, branches of tree etc. (khori) for cooking as fuel in both the beels (Table 1).

Table 1. Physical capital of sampled households by farmer type and well-being.

\begin{tabular}{|c|c|c|c|c|c|c|c|c|c|c|c|c|}
\hline & \multicolumn{4}{|c|}{ Poor } & \multicolumn{4}{|c|}{ Marginal } & \multicolumn{4}{|c|}{ Better-off } \\
\hline & RB-1 & RB-2 & BB-1 & BB-2 & RB-1 & RB-2 & BB-1 & BB-2 & RB-1 & RB-2 & BB-1 & BB-2 \\
\hline \multicolumn{13}{|c|}{ Residence (Percent and No of HH) } \\
\hline Own house & $\begin{array}{l}21.74 \\
(10)\end{array}$ & $\begin{array}{l}8.70 \\
(4)\end{array}$ & $\begin{array}{l}2.70 \\
(2)\end{array}$ & $\begin{array}{l}2.70 \\
(2)\end{array}$ & $\begin{array}{l}67.39 \\
(31)\end{array}$ & $\begin{array}{l}54.35 \\
(25)\end{array}$ & $\begin{array}{l}58.11 \\
(43)\end{array}$ & $\begin{array}{l}56.76 \\
(42)\end{array}$ & $8.70(4)$ & $34.78(16)$ & $\begin{array}{l}39.19 \\
(29)\end{array}$ & $\begin{array}{l}40.54 \\
(30)\end{array}$ \\
\hline Others house & $\mathbf{0}$ & $\mathbf{0}$ & $\mathbf{0}$ & $\mathbf{0}$ & $\mathbf{0}$ & $\mathbf{0}$ & $\mathbf{0}$ & $\mathbf{0}$ & $2.17(1)$ & $2.17(1)$ & $\mathbf{0}$ & $\mathbf{0}$ \\
\hline \multicolumn{13}{|c|}{ Housing Status (Percent and No of HH) } \\
\hline Pacca & $\mathbf{0}$ & $\mathbf{0}$ & $\mathbf{0}$ & $\mathbf{0}$ & $2.17(1)$ & $2.17(1)$ & $1.35(1)$ & $1.35(1)$ & $\mathbf{0}$ & $\mathbf{0}$ & $\mathbf{0}$ & $\mathbf{0}$ \\
\hline Semi pacca & $\mathbf{0}$ & $\mathbf{0}$ & $\mathbf{0}$ & $\mathbf{0}$ & $\mathbf{0}$ & $\mathbf{0}$ & $5.41(4)$ & $5.41(4)$ & $6.52(3)$ & $6.52(3)$ & $2.70(2)$ & $2.70(2)$ \\
\hline Tin tin & $\begin{array}{l}10.87 \\
(5)\end{array}$ & $\begin{array}{l}6.52 \\
(3)\end{array}$ & $\begin{array}{l}2.70 \\
(2)\end{array}$ & $\begin{array}{l}1.35 \\
(1)\end{array}$ & $\begin{array}{l}32.61 \\
(15)\end{array}$ & $\begin{array}{l}21.74 \\
(10)\end{array}$ & $\begin{array}{l}24.32 \\
(18)\end{array}$ & $25.68(19)$ & $2.17(1)$ & $17.39(8)$ & $\begin{array}{l}28.38 \\
(21)\end{array}$ & $\begin{array}{l}28.38 \\
(21)\end{array}$ \\
\hline $\begin{array}{l}\text { Tin } \\
\text { stick }\end{array}$ & $\begin{array}{l}10.87 \\
(5)\end{array}$ & $\begin{array}{l}2.17 \\
(1)\end{array}$ & & $\begin{array}{l}1.35 \\
(1)\end{array}$ & $\begin{array}{l}32.61 \\
(15)\end{array}$ & $\begin{array}{l}30.43 \\
(14)\end{array}$ & $\begin{array}{l}27.03 \\
(20)\end{array}$ & $24.32(18)$ & $2.17(1)$ & $13.04(6)$ & $8.11(6)$ & $9.46(7)$ \\
\hline \multicolumn{13}{|c|}{ Electricity Availability (Percent and No of $\mathrm{HH}$ ) } \\
\hline Have & $\begin{array}{l}13.04 \\
(6)\end{array}$ & $\begin{array}{l}4.35 \\
(2)\end{array}$ & $\begin{array}{l}1.35 \\
(1)\end{array}$ & $\begin{array}{l}1.35 \\
(1)\end{array}$ & $\begin{array}{l}19.57 \\
(9)\end{array}$ & $\begin{array}{l}23.91 \\
(11)\end{array}$ & $\begin{array}{l}45.95 \\
(34)\end{array}$ & $44.59(33)$ & $6.52(3)$ & $10.87(5)$ & $\begin{array}{l}28.38 \\
(21)\end{array}$ & $\begin{array}{l}29.73 \\
(22)\end{array}$ \\
\hline Have not & $\begin{array}{l}8.70 \\
(4)\end{array}$ & $\begin{array}{l}4.35 \\
(2)\end{array}$ & $\begin{array}{l}1.35 \\
(1)\end{array}$ & $\begin{array}{l}1.35 \\
(1)\end{array}$ & $\begin{array}{l}47.83 \\
(22)\end{array}$ & $\begin{array}{l}30.43 \\
(14)\end{array}$ & $\begin{array}{l}12.16 \\
(9)\end{array}$ & $12.16(9)$ & $4.35(2)$ & $\begin{array}{l}26.09 \\
(12)\end{array}$ & $9.46(7)$ & $9.46(7)$ \\
\hline \multicolumn{13}{|c|}{ Drinking Water (Percent and No of $\mathrm{HH}$ ) } \\
\hline Supply & $\mathbf{0}$ & $\mathbf{0}$ & $\mathbf{0}$ & $\mathbf{0}$ & $\mathbf{0}$ & $\mathbf{0}$ & $\mathbf{0}$ & $\mathbf{0}$ & $\mathbf{0}$ & $\mathbf{0}$ & $\mathbf{0}$ & $\mathbf{0}$ \\
\hline Tube well & $\begin{array}{l}21.74 \\
(10)\end{array}$ & $\begin{array}{l}8.70 \\
(4)\end{array}$ & $\begin{array}{l}2.70 \\
(2)\end{array}$ & $\begin{array}{l}2.70 \\
(2)\end{array}$ & $\begin{array}{l}67.39 \\
(31)\end{array}$ & $\begin{array}{l}54.35 \\
(25)\end{array}$ & $\begin{array}{l}58.11 \\
(43)\end{array}$ & $56.76(42)$ & $10.87(5)$ & $36.96(17)$ & $\begin{array}{l}39.19 \\
(29)\end{array}$ & $\begin{array}{l}40.54 \\
(30)\end{array}$ \\
\hline \multicolumn{13}{|c|}{ Sanitary Facillities (Percent and No of HH) } \\
\hline Pacca & $\mathbf{0}$ & $\mathbf{0}$ & $\mathbf{0}$ & $\mathbf{0}$ & $\mathbf{0}$ & $\mathbf{0}$ & $4.05(3)$ & $4.05(3)$ & $\mathbf{0}$ & $\mathbf{0}$ & $1.35(1)$ & $1.35(1)$ \\
\hline
\end{tabular}




\begin{tabular}{|c|c|c|c|c|c|c|c|c|c|c|c|c|}
\hline $\begin{array}{l}\text { Pit covered } \\
\text { by Slab }\end{array}$ & $\begin{array}{l}21.74 \\
(10)\end{array}$ & $\begin{array}{l}8.70 \\
(4)\end{array}$ & $\begin{array}{l}2.70 \\
(2)\end{array}$ & $\begin{array}{l}2.70 \\
(2)\end{array}$ & $\begin{array}{l}67.39 \\
(31)\end{array}$ & $\begin{array}{l}54.35 \\
(25)\end{array}$ & $\begin{array}{l}54.05 \\
(40)\end{array}$ & $52.70(39)$ & $10.87(5)$ & $\begin{array}{l}36.96 \\
(17)\end{array}$ & $\begin{array}{l}37.84 \\
(28)\end{array}$ & $\begin{array}{l}39.19 \\
(29)\end{array}$ \\
\hline \multicolumn{13}{|c|}{ Source of Fuel (Percent and No of $\mathbf{H H}$ ) } \\
\hline Khori & $\begin{array}{l}21.74 \\
(10)\end{array}$ & $\begin{array}{l}8.70 \\
(4)\end{array}$ & $\begin{array}{l}2.70 \\
(2)\end{array}$ & $\begin{array}{l}2.70 \\
(2)\end{array}$ & $\begin{array}{l}67.39 \\
(31)\end{array}$ & $\begin{array}{l}54.35 \\
(25)\end{array}$ & $\begin{array}{l}58.11 \\
(43)\end{array}$ & $56.76(42)$ & $10.87(5)$ & $\begin{array}{l}36.96 \\
(17)\end{array}$ & $\begin{array}{l}39.19 \\
(29)\end{array}$ & $\begin{array}{l}40.54 \\
(30)\end{array}$ \\
\hline
\end{tabular}

Figure in the parenthesis indicates the number $(\mathrm{N})$

\subsection{Human capital}

Human Capital is a category of livelihood assets. It represents the skills, knowledge, capacity to work and good health that together enable people to pursue different livelihood strategies and achieve their livelihood outcomes.

\subsubsection{Age group}

The age of the household heads $(\mathrm{HHH})$ was ranged between 20 years and 63 years with an average of $37.46( \pm) 1.354$ years and 38.46( \pm )1.354 years for RB-1 and RB-2, respectively whereas for BB-1 and BB-2 the average age were $38.00( \pm) 1.064$ and 39.00( \pm )1.064, respectively (Table 2).

Table 2. Mean age of fishers (HHH) by location and year in RB and BB.

\begin{tabular}{|l|l|l|l|l|}
\hline \multirow{2}{*}{$\begin{array}{l}\text { Year / } \\
\text { Site }\end{array}$} & \multicolumn{2}{|c|}{ 1st year } & \multicolumn{2}{c|}{ 2nd year } \\
\cline { 2 - 5 } & Ruhul beel & Bamonji beel & Ruhul beel & Bamonji beel \\
\hline Mean & $37.46( \pm) 1.354$ & $38.00( \pm) 1.064$ & $38.46( \pm) 1.354$ & $39.00( \pm) 1.064$ \\
\hline Maximum & 62 & 58 & 63 & 59 \\
\hline Minimum & 20 & 22 & 21 & 23 \\
\hline
\end{tabular}

The second highest group was young aged group $(\geq 30<50$ ) which was ranged from $16.22 \%$ to $25.68 \%$ in BB-2 and BB-1, respectively. The old aged ( $>50$ years) fishers $\mathrm{HHH}$ were the lowest in numbers. The medium aged group fishermen were dominant in RB than $\mathrm{BB}$. There were no significant difference $(\mathrm{P}>0.05)$ found between the age groups by well-being.

\subsubsection{Family size}

The overall mean household size of the fishers' population surveyed for both beel were from $4.70 \pm 1.24$ to $4.76 \pm 1.12$ for $\mathrm{RB}$ and $4.53 \pm 1.10$ to $4.55 \pm 1.05$ for $\mathrm{BB}$ ranging from 2 to 7 for both the beels (Table 3 ). The largest family size was found in poor for both beel and the comparatively smaller sized family was found in marginal for both the beels (Figure 1). Family size was not affected by well-being, location and years ( $>0.05)$.

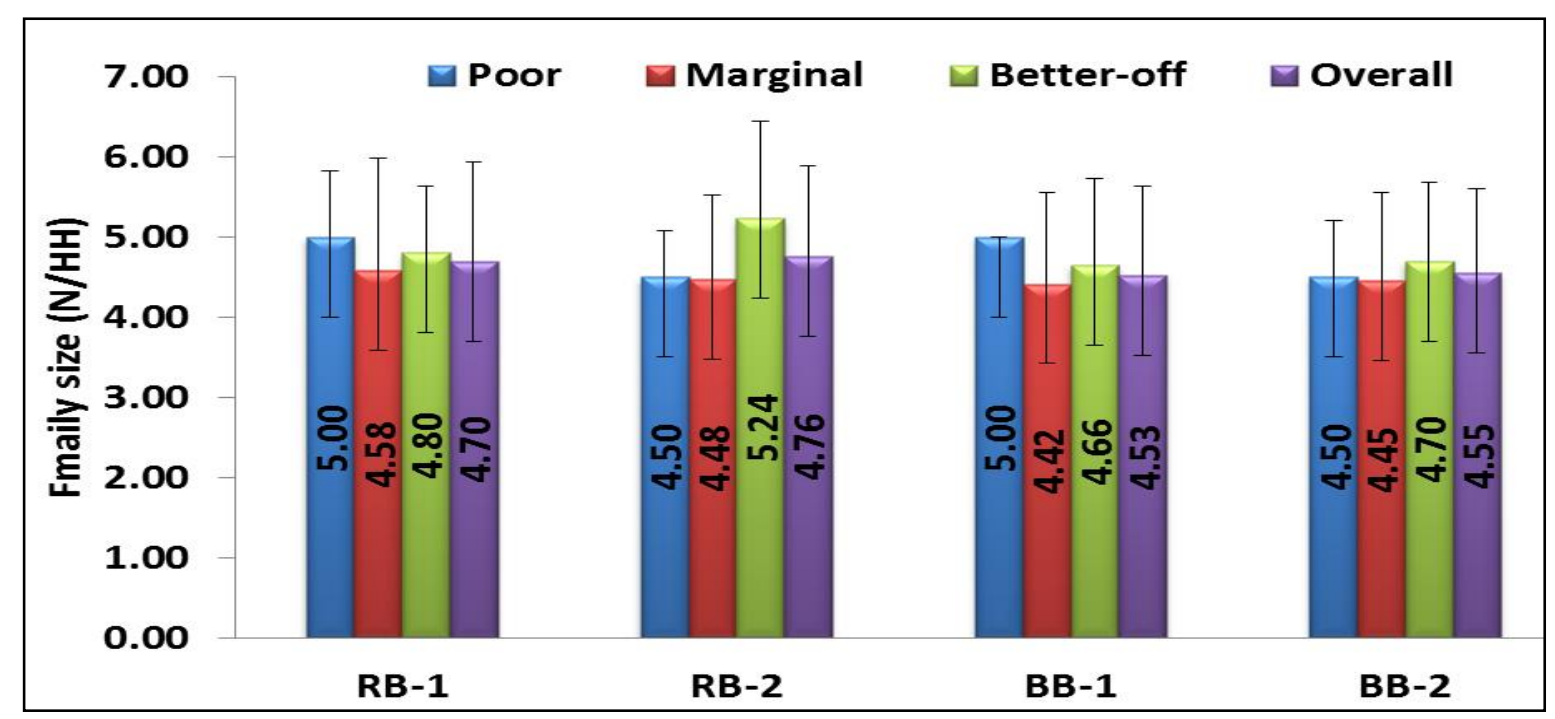

Figure 1. Family size of fishers in RB and BB. 
Table 3. Average numbers of members in the fisher's family with standard error by well-being.

\begin{tabular}{|l|l|l|l|l|l|l|l|l|}
\hline \multirow{2}{*}{ Well-being category } & \multicolumn{2}{|c|}{ RB-1 } & \multicolumn{2}{c|}{ RB-2 } & \multicolumn{2}{c|}{ BB-1 } & \multicolumn{2}{c|}{ BB-2 } \\
\cline { 2 - 9 } & Mean & SD & Mean & SD & Mean & SD & Mean & SD \\
\hline \hline Poor & 5.00 & 0.82 & 4.50 & 0.58 & 5.00 & 0.00 & 4.50 & 0.71 \\
\hline Marginal & 4.58 & 1.41 & 4.48 & 1.05 & 4.42 & 1.14 & 4.45 & 1.11 \\
\hline Better-off & 4.80 & 0.84 & 5.24 & 1.20 & 4.66 & 1.08 & 4.70 & 0.99 \\
\hline Average of total & 4.70 & 1.24 & 4.76 & 1.12 & 4.53 & 1.10 & 4.55 & 1.05 \\
\hline
\end{tabular}

\subsubsection{Marrital status}

All the household heads were married except $2 \%$ from marginal fishermen of RB-1 and $4 \%$ from better-off of BB-1 however, 1\% unmarried was found from marginal of BB-1 and BB-2 (Figure 2). There was no significant differences (ANOVA; P>0.05, F= 0.722) between marrital status of fishers among location, seasons and wellbeing.

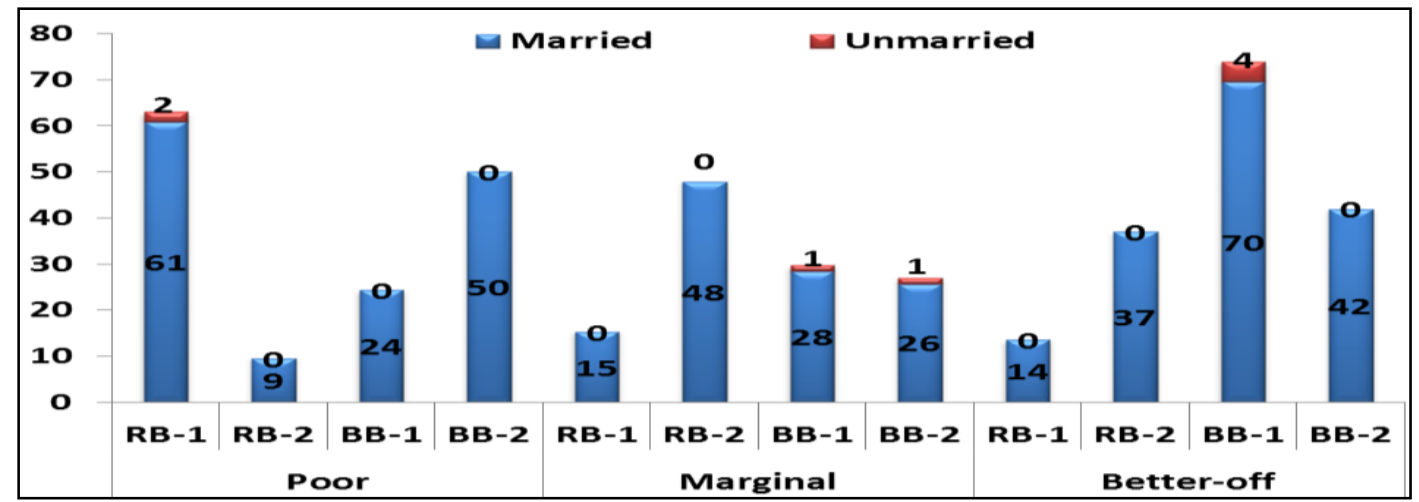

Figure 2. Distribution of marital status by location, season and well-being in RB and BB.

\subsubsection{Educational status}

Education is a basic right of all population, along with food, cloth and medication. Educational qualification of the fishers (HHH) of the study spot was highest up to JSC. The majority of fishers were able to sign only (Figure 3). Overall 1\% to 7\% HHHs was literate up to PSC from different well-being categories. There was no JSC passed fishermen in RB and BB in better-off and poor category, respectively. The highest numbers of HHH were able to sign only and the capabilities of sign in better-off family were increased ( $8 \%$ to $26 \%$ ) after establishing the sanctuary. There was no significant differences in (ANOVA; P=.077, F=2.589) education by site, year and well-being. Chi-square test shows that there was a significant variation in education $(\chi 2=17.14 \mathrm{a}$, $\mathrm{P}<0.01$ for RB-1 and RB-2) by well-being categories. However, there was no significant variation $\left(\chi 2=2.488^{\mathrm{b}}\right.$ and $4.365^{\mathrm{C}}$ for BB-1 and BB-2, P>0.05) within family size, site and year (Table 4) both for BB-1 and BB-2.

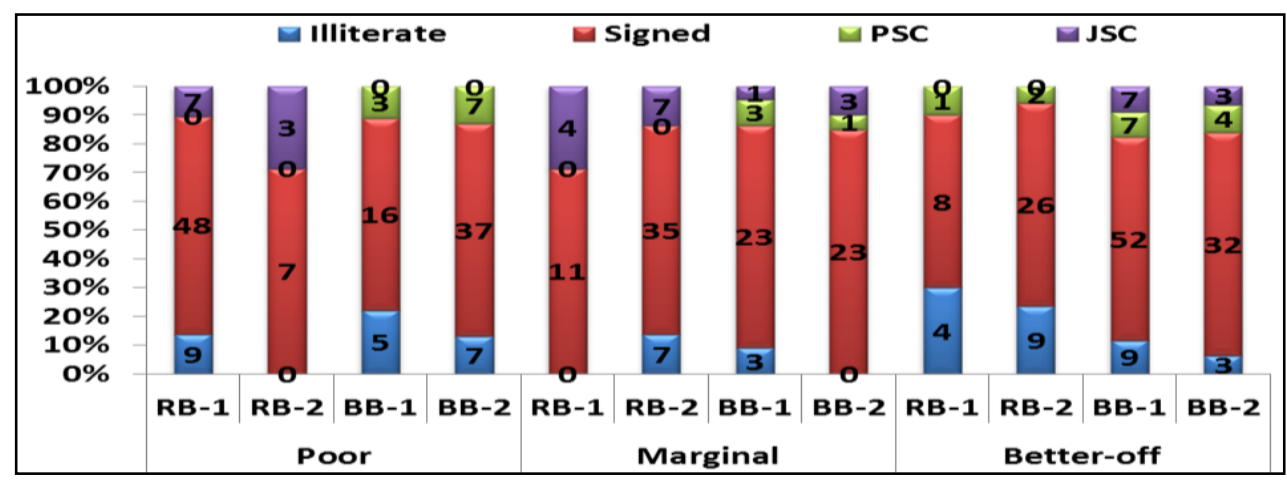

Figure 3. Educational status of fishers HHH in RB and BB by location, well-being. 
Table 4. Result of Chi-Square Tests (Education * Family Size * Site * Year Cross tabulation).

\begin{tabular}{l|l|l|l|l|l|l}
\hline \hline \multirow{2}{*}{ Site } & \multirow{3}{*}{ Chi-Square Tests } & \multicolumn{4}{c|}{ Family size } & \multicolumn{2}{c}{ Well-being } \\
\cline { 3 - 7 } & & df & $\chi^{\mathbf{2}}$ Value & $\begin{array}{l}\text { Asymp. Sig. } \\
\text { (2-sided) }\end{array}$ & $\chi^{\mathbf{2}}$ Value & $\begin{array}{l}\text { Asymp. Sig. } \\
\text { (2-sided) }\end{array}$ \\
\hline \hline RB-1 & Pearson Chi-Square & 241 & $17.140^{\mathrm{a}}$ & 0.009 & $11.444(\mathrm{a})$ & 0.076 \\
RB-2 & Pearson Chi-Square & 241 & $17.140^{\mathrm{a}}$ & 0.009 & $6.454(\mathrm{c})$ & 0.374 \\
BB-1 & Pearson Chi-Square & 241 & $2.488^{\mathrm{b}}$ & 0.870 & $12.427(\mathrm{~b})$ & 0.053 \\
BB-2 & Pearson Chi-Square & 241 & $4.365^{\mathrm{c}}$ & 0.627 & $8.421(\mathrm{a})$ & 0.209 \\
\hline \hline
\end{tabular}

\subsubsection{School going and dropout children}

The result of school going and dropout children has shown in the Figure 4 and Table 5. The total children were $124 \pm 0.18,128 \pm 0.16,187 \pm 0.12$ and $189 \pm 0.13$ in RB-1, RB-2, BB-1 and BB-2, respectively. The percent of school going children were 78.23\%, 92.97\%, 68.56\% and 66.67\% in RB-1, RB-2, BB-1 and BB-2, respectively. The school going rate was increased $22.68 \%$ in RB but decreased $1.56 \%$ in BB. Percentage of dropout children was $17.84 \%, 8.40 \%, 38.28 \%$ and $48.41 \%$ in RB-1, RB-2, BB-1 and BB-2, respectively (Table 5). On the other hand, dropout percent was decreased $41.18 \%$ in RB but increased $24.49 \%$ in BB (Figure 4). There was a significant difference in school going (ANOVA; $\mathrm{P}<0.001, \mathrm{~F}=41.13$ ) and dropout children $(\mathrm{P}<0.001, \mathrm{~F}=11.48)$ in different sites but there was no significant difference in total children $(\mathrm{P}>0.05, \mathrm{~F}=1.833)$ among different sites (Table 5a).

Table 5. Educational status of children during the study period in RB and BB.

\begin{tabular}{l|l|l|l|l|l}
\hline Site/Year & Total Children & Total SGC & \% of SGC & Total DOC & \% of DOC \\
\hline RB-1 & $124 \pm 0.18$ & $97 \pm 0.14$ & 78.23 & $17 \pm 0.08$ & 17.53 \\
RB-2 & $128 \pm 0.16$ & $119 \pm 0.13$ & 92.97 & $10 \pm 0.06$ & 8.40 \\
Changes (\%) & $3.23 \%$ & & $22.68 \%$ & & $-41.18 \%$ \\
BB-1 & $187 \pm 0.12$ & $128 \pm 0.06$ & 68.45 & $49 \pm 0.08$ & 38.28 \\
BB-2 & $189 \pm 0.13$ & $126 \pm 0.07$ & 66.67 & $61 \pm 0.09$ & 48.41 \\
Changes (\%) & 1.07 & -1.56 & & 24.49 \\
\hline \hline
\end{tabular}

SGC= School going children, $\mathrm{DOC}=$ Drop out children

Table 5a. ANOVA result for total schooling going, dropout and total children.

\begin{tabular}{|l|l|l|l|l|l|l|}
\hline ANOVA Table & & SS & df & MS & F & Sig. \\
\hline Total School Going*Site & Between Groups & 22.63 & 1 & 22.63 & 41.13 & 0.00 \\
\hline Total Drop out*Site & Between Groups & 11.48 & 1 & 11.48 & 28.07 & 0.00 \\
Total Children*Site & Between Groups & 2.237 & 1 & 2.237 & 1.833 & 0.177 \\
\hline
\end{tabular}

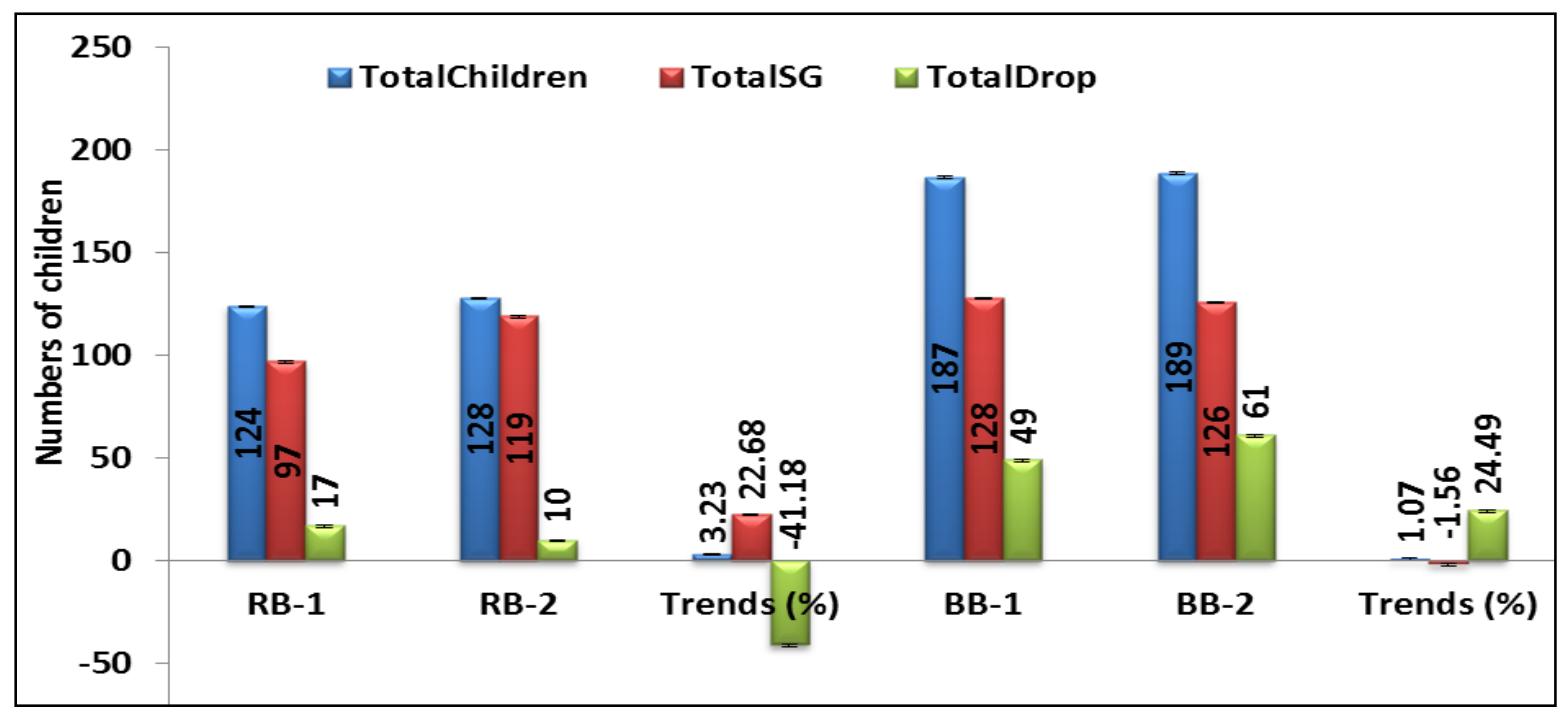

Figure 4. Changing trends (\%) of school going and dropout children RB and BB. 


\subsubsection{Occupation}

The frequency of fishers HH by occupation has shown in Table 6. Overall $100 \%$ fisher's main occupation was fishing in case of RB in both the years whereas in case of BB fishing was the main occupation of 38\% in BB-1 and $27 \%$ in BB-2. Business as secondary occupation was added $2.17 \%$ in RB. In BB fishing as main occupation was decreased $28.95 \%$. Agriculture and daily laborer as main occupation was increased $116.67 \%$ and $71.43 \%$, respectively in $\mathrm{BB}$.

Table 6. Frequency of fisher's households according to occupation (main and secondary).

\begin{tabular}{|c|c|c|c|c|c|c|}
\hline \multirow{2}{*}{$\begin{array}{l}\text { Occupation } \\
\text { RB }\end{array}$} & \multicolumn{2}{|c|}{ Main } & \multirow{2}{*}{ Trends (\%) } & \multicolumn{2}{|c|}{ Secondary } & \multirow{2}{*}{$\begin{array}{l}\text { Trends } \\
(\%)\end{array}$} \\
\hline & 1st year & 2nd year & & 1st year & 2nd year & \\
\hline None & 0 & 0 & & 3 & 2 & -33.33 \\
\hline Fishing & 46 & 46 & & 0 & 0 & 0 \\
\hline Agriculture & 0 & 0 & & 6 & 6 & 0 \\
\hline Business & 0 & 0 & & 0 & 1 & 2.17 \\
\hline \multirow{2}{*}{ Daily labour } & 0 & 0 & & 37 & 37 & 0 \\
\hline & 46 & 46 & & 46 & 46 & 0 \\
\hline \multicolumn{7}{|l|}{ BB } \\
\hline None & 0 & 0 & & 0 & 0 & 0 \\
\hline Fishing & 38 & 27 & -28.95 & 36 & 47 & 30.56 \\
\hline Agriculture & 6 & 13 & 116.67 & 15 & 8 & -46.67 \\
\hline Business & 23 & 22 & -4.35 & 14 & 15 & 7.14 \\
\hline \multirow[t]{2}{*}{ Daily labour } & 7 & 12 & 71.43 & 9 & 4 & -55.56 \\
\hline & 74 & 74 & & 74 & 74 & 0 \\
\hline
\end{tabular}

\subsubsection{Primary occupation by location, season and well-being}

The result of the main occupation is shown in the Figure 5. The 100\% fishermen's main occupation was fishing for all well-being categories of RB, however in case of BB agriculture, business and daily labor was the main occupation in some of poor, marginal and better-off category. The main occupation as business was increased in poor ( $4 \%$ to $11 \%)$, marginal (9\% to $12 \%$ ) but decreased in better-off ( $28 \%$ to $11 \%)$. On the other hand, the main occupation agriculture of the fishers was increased in marginal (1\% to 3\%) and better-off (11\% to 15\%) categories for $\mathrm{BB}$ that is the trends to migrate towards agriculture from fishing as main occupation were observed in BB of marginal and better-off categories. Fishing was the main occupation of $63 \%$ fishers in poor category which was decreased to $9 \%$ after establishing the sanctuary which indicates the upliftment of wellbeing. Fishing was increased as main occupation in marginal (15\% to $48 \%$ ) and better-off (14\% to $37 \%$ ) category of $\mathrm{RB}$ whereas decreased in $\mathrm{BB}$ as shown in Figure 5. There was a highly significant differences (ANOVA; $\mathrm{P}<0.001, \mathrm{~F}=7.169$ ) in main occupation among all well-being categories (Table 6a).

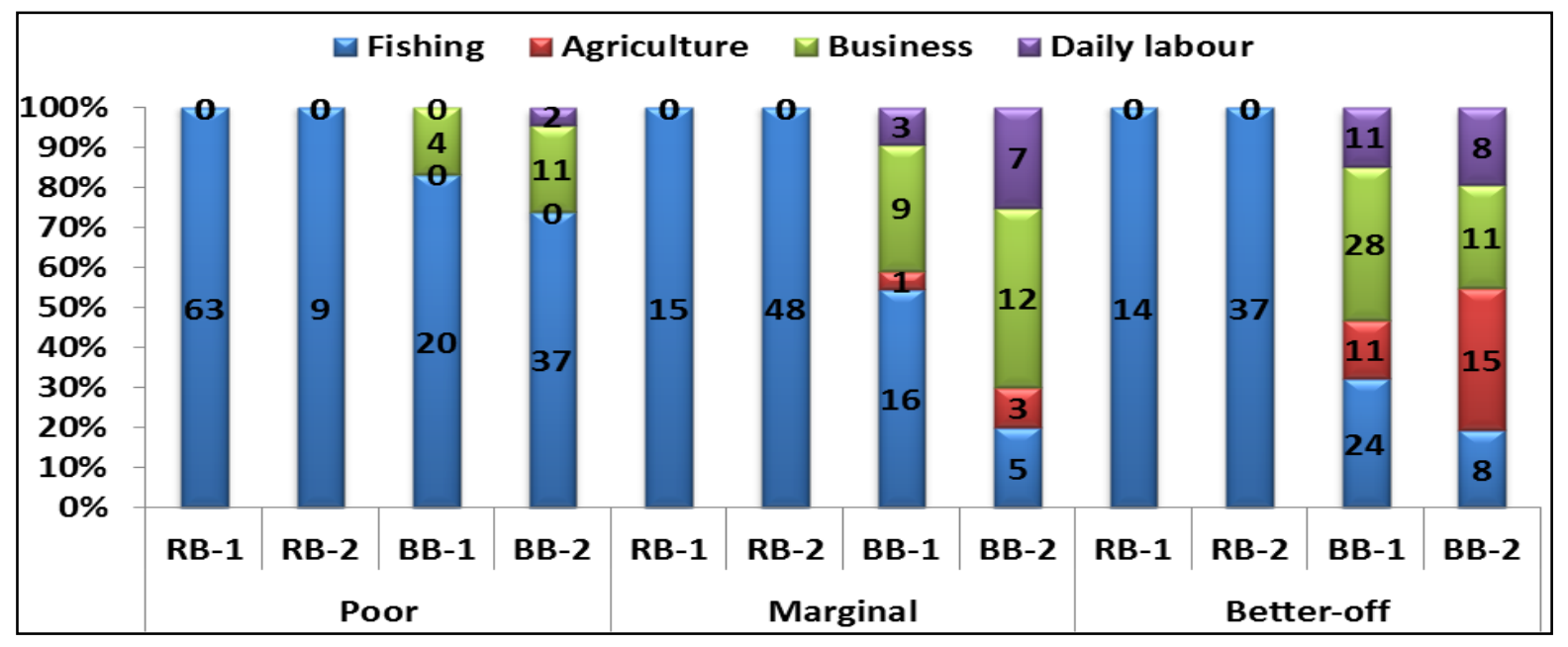

Figure 5. Distribution of fisher's household according to primary occupation by location, year and wellbeing. 
Table 6a. The ANOVA results for main and secondary occupation by well-being.

\begin{tabular}{l|l|l|l|lc}
\hline & SS & df & MS & F & Sig. \\
\hline \multicolumn{7}{c}{} & ANOVA Table (Main occupation * Well-being) & \\
\hline Between Groups & 14.55817 & 2 & 7.279085 & 7.169421 & 0.001 \\
Within Groups & 240.6252 & 237 & 1.015296 & \\
Total & 255.1833 & 239 & & \\
\hline \multicolumn{7}{c}{ ANOVA Table (Secondary occupation * Well-being) } \\
\hline \hline Between Groups & 48.39181 & 2 & 24.19591 & 0.001 \\
Within Groups & 381.2707 & 237 & 1.608737 & \\
Total & 429.6625 & 239 & & \\
\hline \hline
\end{tabular}

\subsubsection{Secondary occupation by location, season and well-being}

The result of the secondary occupation has shown in the Figure 6. Daily labour was the dominant secondary occupation in RB by all well-being categories; however, fishing was the dominant secondary occupation in BB by marginal and better-off categories. The secondary occupation as fishing was increased in BB by $4 \%$ to $8 \%$ in poor, $14 \%$ to $22 \%$ in marginal and $31 \%$ to $34 \%$ in better-off category (Figure 6) whereas agriculture as secondary occupation was increased for RB in marginal well-being (4\% to $8 \%$ ). In case of RB in better-off category business was increased (upto 2\%). The migrating trend in fishing was observed in BB of marginal and better-off categories towards secondary occupation. There was a significant difference (ANOVA; P $<0.001$, $\mathrm{F}=15.04$ ) in secondary occupations among the well-being categories (Table 6a).

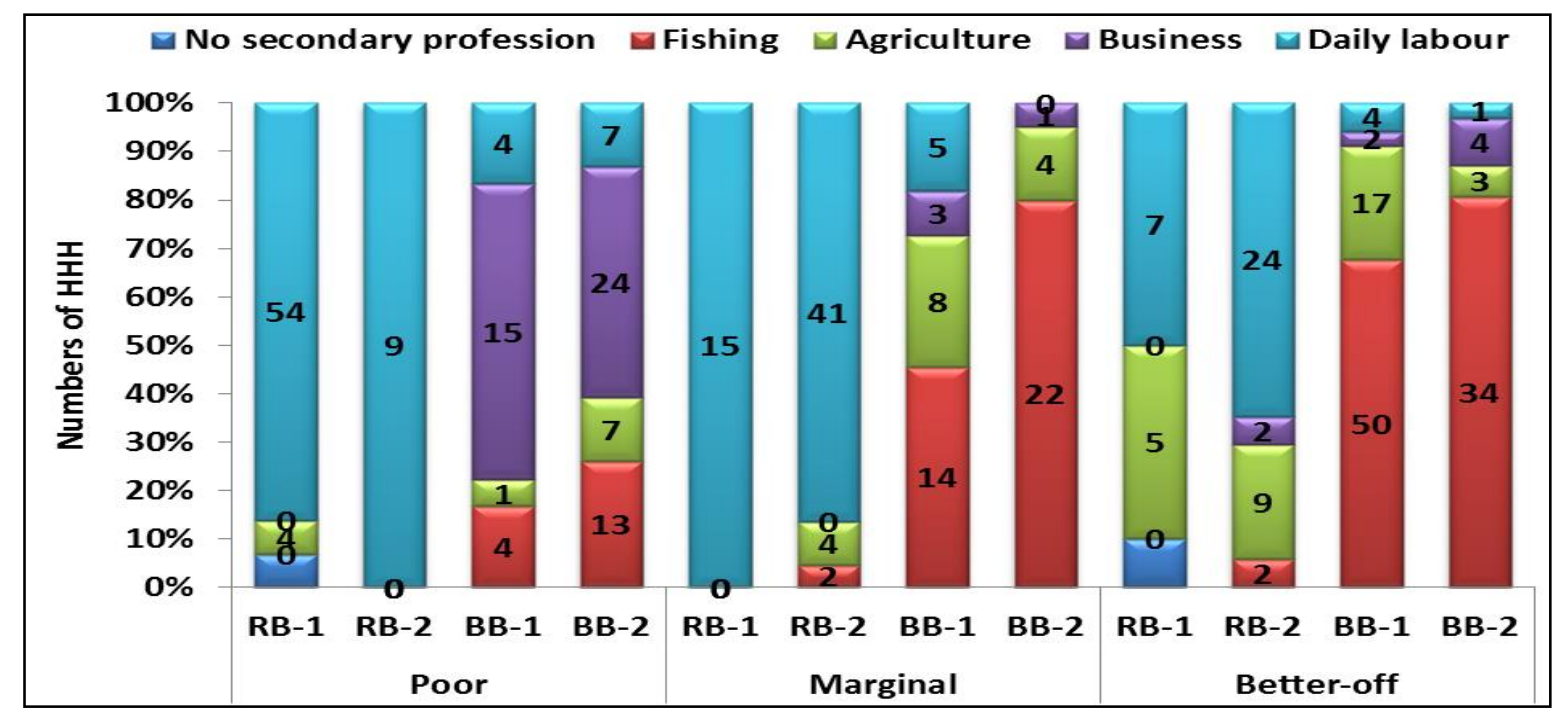

Figure 6. Distribution of fisher's household according to secondary occupation by location, season and well-being.

\subsection{Financial capital}

Financial Capital is a category of livelihood assets. Within the SL framework, it is defined as the financial resources that people use to achieve their livelihood objectives.

\subsubsection{Income}

The results of total income have been presented in the Table 7. Traditionally although fishing is the major and in some cases only source of income for fishers, individuals occasionally undertaken a variety of supplementary activities (business, agriculture, livestock, labour and others sources) which constitute a substantial part of their annual income. In the present study, the mean total income from all the sources together were $887.03 \pm 259.62$, $1007.46 \pm 281.35,991.06 \pm 271.78$ and $943.78 \pm 264.94$ for RB-1, RB-2, BB-1 and BB-2, respectively which was ranged from 547.50 to 1884.76 US\$ for RB (both year together) and 438.09 to 1784.02 US\$ for BB (both year together). The highest part of income were come from fishing contributing 63.9\% (566.84 \pm 107.83 US\$), $64.89 \%$ (653.72 \pm 128.82 US\$), $43.58 \%$ (431.89 \pm 74.66 US\$) and $39.60 \%$ (373.70 \pm 62.34 US\$) for RB-1, RB-2, BB-1 and BB-2, respectively. The second highest income was from livestock in case of RB (15.2\%) whereas in 
case of BB the second highest income was added to total income from agriculture (23.17\%). The income from all the sources was increased by $13.58 \%$ in case of RB however, income decreased by $4.77 \%$ in $\mathrm{BB}$. There was no differences in yearly mean income by well-being between years $(\mathrm{P}>0.0)$ sites $(\mathrm{P}>0.05)$ (Table 7a). Comparison between total income and national is shown in Table 8.

Table 7. Mean income of the $\mathrm{HH}$ of $\mathrm{RB}$ and $\mathrm{BB}$.

\begin{tabular}{|ll|llllc|}
\hline Site & Year & N & Mean & Std. Deviation & Minimum & Maximum \\
\hline \hline \multirow{2}{*}{ Ruhul beel } & 1st year & 46 & 887.03 & 259.62 & 625.77 & 1884.76 \\
& 2nd year & 46 & 1007.46 & 281.35 & 547.50 & 1722.53 \\
Bamonji beel & 1st year & 74 & 991.06 & 271.78 & 438.09 & 1722.61 \\
& 2nd year & 74 & 943.78 & 264.94 & 520.27 & 1784.02 \\
& & & & & & \\
\hline
\end{tabular}

Table 7a. Analysis of variance (ANOVA) of the effects of sites and years on mean income of fishers in RB and $\mathrm{BB}$.

\begin{tabular}{l|c|c|c|c|c|c|}
\hline & & SS & df & MS & F & Sig. \\
\hline \hline Total Income * Year & Between Groups & 17354.96 & 1 & 17354.96 & 0.24 & 0.628 \\
Total Income * Site & Between Groups & 23102.55 & 1 & 23102.55 & 0.31 & 0.576 \\
\hline \hline
\end{tabular}

$\mathrm{SS}=$ Sum of squeres, MS = Mean of squres and $\mathrm{df}=$ degree of freedom.

Table 8. Comparison between total income and national.

\begin{tabular}{|l|l|l|l|l|l|}
\hline & & \multicolumn{2}{|c|}{ 1st year } & \multicolumn{2}{c|}{ 2nd year } \\
\hline & & HHH & $\%$ & HHH & \% \\
\hline \multirow{2}{*}{ Ruhul beel } & $\leq$ National average Income & 41 & 89.13 & 38 & 82.61 \\
& $>$ National average Income & 5 & 10.87 & 8 & 17.39 \\
& Total & 46 & 100 & 46 & 100 \\
Bamonji beel & $\leq$ National average Income & 62 & 83.78 & 65 & 87.84 \\
& $>$ National average Income & 12 & 16.22 & 9 & 12.16 \\
& Total & 74 & 100 & 74 & 100 \\
\hline
\end{tabular}

\subsection{Food and Nutrition}

\subsubsection{Monthly frequency of $\mathrm{HH}$ by food intake}

Total $46 \mathrm{HH}$ from RB and $74 \mathrm{HH}$ from $\mathrm{BB}$ were observed for food intake survey. The fish intake was found to increase in marginal and better-off household and to decrease in poor HH for RB. Fish intake among the wellbeing categories, location and year was varied significantly $(\chi 2=9.56,16.11,12.85,15.20$; and $\mathrm{P}<0.01,0.001$, $0.05,0.01$ for RB-1, RB-2, BB-1 and BB-2, respectively). The meat, egg and milk consumption frequency in poor households was decreased however increased in marginal and better-off category. Consumption frequency of meat (day/HH/month) was not significantly different among by well-being, locatin and year $(\mathrm{P}>0.05)$. The egg intake frequency in all the fishers from both beels were $<10$ days per month other than only one household in marginal of RB-2 (Table 9). The egg intake was significantly $(\mathrm{P}<0.001)$ affected in RB by well-being, loction and year however not in BB $(\mathrm{P}>0.05)$ (Table 9a). Milk intake was not significantly $(\mathrm{P}>0.05)$ affected by the variation in total income, sites and years for both the beels. 
Table 9. Monthly food intake (HH/month) by well-being and rank (Very low $=\leq 10$, low $=>10 \leq 15$, medium $=>15 \leq 20$, high $=>20$ ).

\begin{tabular}{|c|c|c|c|c|c|c|c|c|c|c|c|c|}
\hline & \multicolumn{4}{|c|}{ Poor } & \multicolumn{4}{|c|}{ Marginal } & \multicolumn{4}{|c|}{ Better-off } \\
\hline & RB-1 & RB-2 & BB-1 & BB-2 & RB-1 & RB-2 & BB-1 & BB-2 & RB-1 & RB-2 & BB-1 & BB-2 \\
\hline \multicolumn{13}{|l|}{ Fish intake } \\
\hline Low $(>10<=15)$ & 0 & 0 & 4 & 6 & 0 & 0 & 4 & 3 & 2 & 2 & 6 & 5 \\
\hline Medium $(>15<=20)$ & 12 & 1 & 9 & 12 & 1 & 8 & 13 & 13 & 3 & 7 & 23 & 20 \\
\hline High $(>20)$ & 17 & 6 & 5 & 5 & 6 & 14 & 5 & 4 & 5 & 8 & 5 & 6 \\
\hline \multicolumn{13}{|l|}{ Meat intake } \\
\hline Very low $(<=10)$ & 29 & 7 & 18 & 23 & 7 & 22 & 22 & 20 & 10 & 17 & 34 & 31 \\
\hline \multicolumn{13}{|l|}{ Egg intake } \\
\hline Very low $(<=10)$ & 29 & 7 & 18 & 23 & 7 & 21 & 22 & 20 & 10 & 17 & 34 & 31 \\
\hline Medium $(>10<=15)$ & 0 & 0 & 0 & 0 & 0 & 1 & 0 & 0 & 0 & 0 & 0 & 0 \\
\hline \multicolumn{13}{|l|}{ Milk intake } \\
\hline Very low $(<=10)$ & 29 & 7 & 18 & 23 & 7 & 22 & 22 & 20 & 10 & 17 & 34 & 31 \\
\hline \multicolumn{13}{|l|}{ Vegetables intake } \\
\hline Very low $(<=10)$ & 5 & 0 & 9 & 12 & 3 & 2 & 7 & 5 & 5 & 1 & 12 & 11 \\
\hline Low $(>10<=15)$ & 16 & 4 & 9 & 11 & 2 & 17 & 14 & 14 & 3 & 14 & 21 & 19 \\
\hline Medium $(>15<=20)$ & 8 & 3 & 0 & 0 & 2 & 3 & 1 & 1 & 2 & 2 & 1 & 1 \\
\hline
\end{tabular}

Table 9a. Chi-square value of Food intake*Total income*Year*Site Cross tabulation.

\begin{tabular}{|c|c|c|c|c|c|c|c|c|c|c|c|}
\hline & & \multicolumn{2}{|c|}{ Fish } & \multicolumn{2}{|c|}{ Meat } & \multicolumn{2}{|c|}{ Egg } & \multicolumn{2}{|l|}{ Milk } & \multicolumn{2}{|l|}{ Vegetables } \\
\hline Year & & PC Value & $\begin{array}{l}\text { Sig. (2- } \\
\text { sided) }\end{array}$ & PC Value & $\begin{array}{l}\text { Sig. (2- } \\
\text { sided) }\end{array}$ & PC Value & $\begin{array}{l}\text { Sig. (2- } \\
\text { sided) }\end{array}$ & Jalue & \begin{tabular}{|l} 
Sig. (2- \\
sided)
\end{tabular} & ue & $\begin{array}{l}\text { Sig. (2- } \\
\text { sided) }\end{array}$ \\
\hline RB-1 & $\mathrm{PC}^{*}$ & 9.561 (a) & 0.008 & 8.836 (a) & 0.065 & 17.145 (a) & 0.000 & $6.121(\mathrm{a})$ & 0.634 & 15.122 (a) & 0.019 \\
\hline RB-2 & $\mathrm{PC}$ & $16.112(b)$ & 0.000 & $5.475(b)$ & 0.065 & $28.053(b)$ & 0.000 & $12.866(b)$ & 0.117 & (b) & 0.001 \\
\hline BB-1 & $\mathrm{PC}$ & $12.852(\mathrm{c})$ & 0.012 & $.816(\mathrm{c})$ & 0.665 & $3.403(\mathrm{c})$ & 0.182 & $13.101(\mathrm{c})$ & 0.665 & $24.265(\mathrm{c})$ & 0.000 \\
\hline BB-2 & $\mathrm{PC}$ & $15.202(\mathrm{~d})$ & 0.004 & $4.586(\mathrm{~d})$ & 0.101 & $1.487(\mathrm{~d})$ & 0.476 & 17.267 (d) & 0.369 & $28.468(\mathrm{~d})$ & 0.000 \\
\hline
\end{tabular}

$\mathrm{PC}=$ Pearson Chi-square

\subsubsection{Contribution of income from fishing in total income}

In all well-being categories for BB, contributions of income from fishing were decreased. But in marginal and better-off categories the income from fishing were increased and decreased in poor (Figure 7).

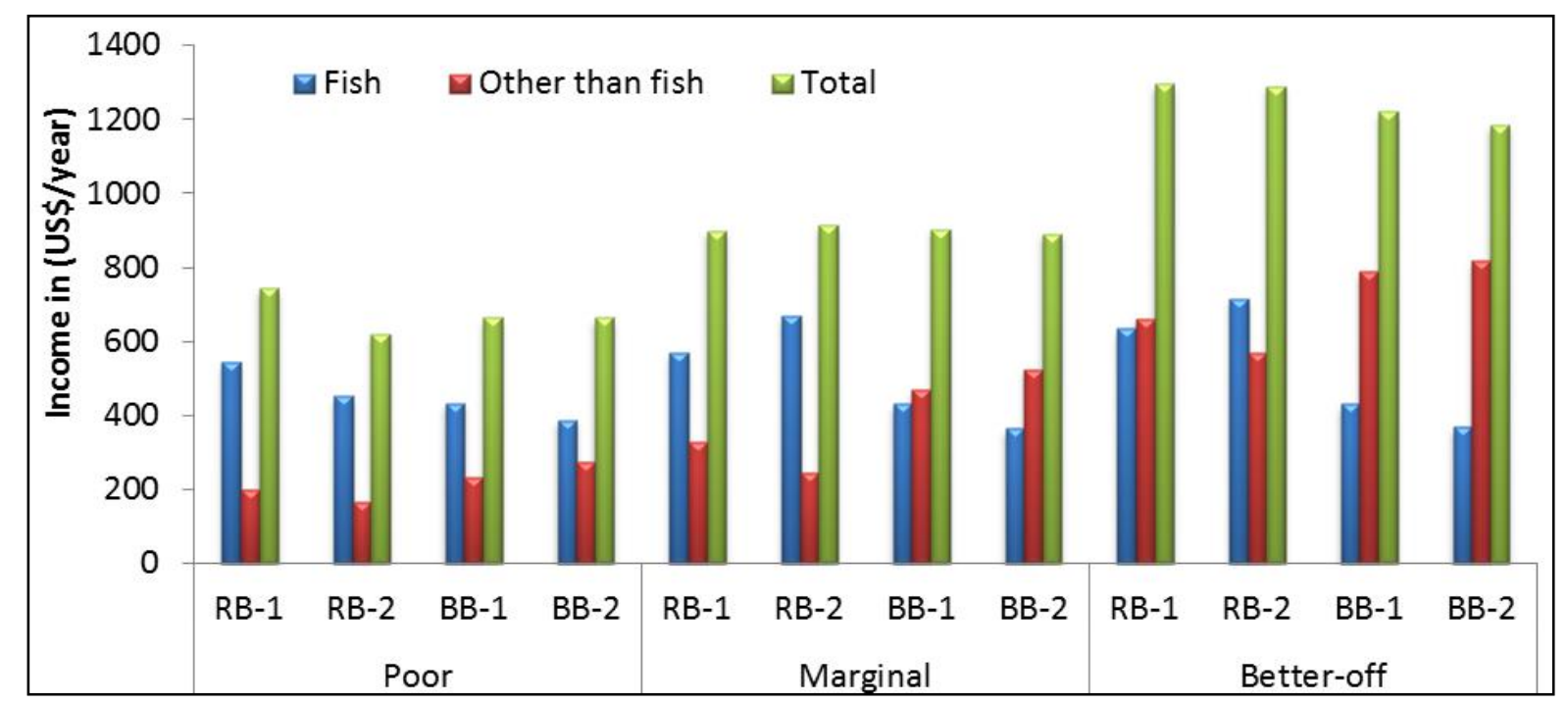

Figure 7. Comparison among total income, income from fishing and in income from other than fishing during the study in RB and BB. 


\subsubsection{Per capita fish intake by well-being groups}

The results of per capita fish intake have been presented in the Table 10. The per capita fish intake was ranged between 46.10 and $55.94 \mathrm{gm} / \mathrm{capita} / \mathrm{day}$ for RB whereas it was ranged between 40.96 and $52.6 \mathrm{gm} / \mathrm{capita} / \mathrm{day}$ for BB during the whole study period. Overall fish intake was increased $11.61 \%$ in RB and decreased $9.77 \%$ in BB. In the poor fish intake/capita/day was increased $4.11 \%$ in RB and decreased $8.19 \%$ in BB whereas in case of marginal and better-off well-being category the fish intake/capita/day was increased $4.77 \%$ and $14.40 \%$ in $\mathrm{RB}$, respectively. However, fish intake/capita/day was decreased $6.59 \%$ and $11.14 \%$ in $\mathrm{BB}$, respectively. There was a significant differences in per capita fish consumption between well-beings $(\mathrm{P}<0.01)$ and location $(\mathrm{P}<0.05)$ but there was no significant differences among years (Table 10a).

Table 10. Per capita fish intake and changing trends.

\begin{tabular}{|c|c|c|c|c|}
\hline Well-Being & Year & Kg/year/capita & gm/day/capita & Trends \\
\hline \multirow{3}{*}{ Poor } & RB-1 & 16.83 & 46.10 & 4.11 \\
& RB-2 & 17.52 & 48.00 & \\
& BB-1 & 16.29 & 44.61 & -8.19 \\
& BB-2 & 14.95 & 40.96 & \\
& RB-1 & 17.99 & 49.29 & 4.77 \\
& RB-2 & 18.85 & 51.64 & \\
& BB-1 & 16.94 & 46.41 & -6.59 \\
& BB-2 & 15.83 & 43.35 & \\
& RB-1 & 17.85 & 48.90 & 14.40 \\
& RB-2 & 20.42 & 55.94 & \\
& BB-1 & 19.00 & 52.06 & -11.14 \\
& BB-2 & 16.89 & 46.26 & \\
& RB-1 & 17.23 & 47.20 & 11.61 \\
& RB-2 & 19.23 & 52.67 & \\
& Boter-off & 17.73 & 48.57 & -9.77 \\
\hline
\end{tabular}

Table 10a. ANOVA Table per capita fish intake and changing trends.

\begin{tabular}{ll|l|l|l|l|l|l|l}
\hline & & & \multicolumn{2}{c|}{ Site } & \multicolumn{2}{c|}{ Well-being } & \multicolumn{2}{c}{ Year } \\
\hline & & df & F & Sig. & F & Sig. & F & Sig. \\
\hline Kg/Cpaita/Year & Between Groups & $1,2,1$ & 6.457 & 0.012 & 6.479 & 0.002 & 0.324 & 0.570 \\
gm/capita/day & Between Groups & $1,2,1$ & 6.457 & 0.012 & 6.482 & 0.002 & 0.324 & 0.570 \\
\hline
\end{tabular}

\subsection{Natural and social capital}

Natural Capital is a category of livelihood assets. It is the term used for the natural resource stocks such as trees, land, clean air, coastal resources upon which people rely for their livelihood.

In the present study, it was found that some household heads have no cultivable land and depended on a small piece of homestead land for housing, food and income. The overall average used land holding was $0.274 \pm 0.136$ ranging 0.065 ha to 0.534 ha for $\mathrm{RB}$ and $0.228 \pm 0.305$ ha ranging 0.040 to 0.267 ha for $\mathrm{BB}$ (Table 11). The average land holdings did not vary significantly $(\mathrm{P}>0.05)$ between the sites.

Table 11. Mean land properties of fishers in RB and BB.

\begin{tabular}{l|l|ll|l|lc}
\hline \multirow{2}{*}{ Sites } & \multirow{2}{*}{ Own Land (ha) } & \multicolumn{2}{|c|}{ Range (ha) } & \multirow{2}{*}{ Lease Land (ha) } & \multicolumn{2}{c}{ Range (ha) } \\
\cline { 3 - 6 } & & Min & Max & & Min & Max \\
\hline RB-1 & $0.274 \pm 0.136$ & 0.065 & 0.534 & $0.136 \pm 0.045$ & 0.040 & 0.267 \\
RB-2 & $0.274 \pm 0.136$ & 0.065 & 0.534 & $0.184 \pm 0.076$ & 0.121 & 0.405 \\
BB-1 & $0.228 \pm 0.305$ & 0.032 & 2.138 & $0.181 \pm 0.105$ & 0.040 & 0.607 \\
BB-2 & $0.228 \pm 0.305$ & 0.032 & 2.138 & $0.181 \pm 0.107$ & 0.040 & 0.607 \\
\hline \hline
\end{tabular}

\section{Discussion}

The nature of residence and housing conditions indicates the social status of the people. During the study it was found that more than $50 \%$ households were marginal by well-being. All the fishers of both beels lived in own house except one from RB. There was no significant variation $(\mathrm{P}>0.05)$ in residences by well-being. All 
together $91.3 \%$ of fishermen's houses were katcha, $6.52 \%$ were semi-pacca and only one fisherman had pucca house in case of RB and in case of BB $90.54 \%$ of fishermen's houses were katcha, $8.11 \%$ were semi-pacca, and only $1.35 \%$ were pucca. There was no significant variation $(\mathrm{P}>0.05)$ among the residences by well-being. The condition of fisher's living house in old Brahmaputra river side and Basantapur beel area were found similar to present study (Rejwan et al., 2012) and Bashar,1995) which indicates that all the fishermen fishing in the freshwater beels and rivers have the same poor housing conditions, it might be due to their poor income. There were no significant effect on residence and housing status with the establishment of fish sanctuary in RB.

Overall 39.23\% 67.30\% household had electricity connection in RB and BB, respectively. The higher number of $\mathrm{HH}$ with electricity availability was of marginal by well-being. It was found that electricity facilities were comparatively lower in RB than that of $\mathrm{BB}$. There were no changes in $\mathrm{RB}$ and $\mathrm{BB}$ with the establishment of fish sanctuary. A significant difference was found between locations (but not between years) for electricity availability $(\mathrm{P}<0.001)$ and sanitation status $(\mathrm{P}<0.001)$. The present result was different from the findings of Shamima (2000) which might be due to the geographical location and socio-economic status of the fishermen.

In case of RB 97\% and in case of BB 89\% fishermen had their own tube-well which is supported by the findings of Rejwan et al. (2012). The status of access to drinking water was not affected by the establishment of sanctuary which is might be due to the access to the safe drinking water was established before sanctuary.

The higher per cent of $\mathrm{HH}$ were found in medium age group in the present study which was also similar to the result of Karim (2006). A slight deviation was found with the findings of Islam (2012) in case of the fishers of Kishoregonj which might be due to the different location. In marginal category, all the age group was increased in RB. In case of BB there was no change in medium and old age group however decreased in young group.

The overall midium sized family was found dominant both for RB $(83 \%)$ and BB $(81 \%)$. The mean household size of the fisher's population surveyed for both beel were from $4.70 \pm 1.24$ to $4.76 \pm 1.12$ for RB and $4.53 \pm 1.10$ to $4.55 \pm 1.05$ for $\mathrm{BB}$ ranging from 2 to 7 for both the beels which was supported with the finding of Karim (2006) and Rejwan et al. (2012). Family size was not affected by well-bing, location and years (P>0.05) in the present study which was supported by (Karim, 2006). The result of the present study showed that bigger size family was found in poor for both beel and the comparatively smaller sized family was found in marginal for both the beels.

From the present study it was observed that all the fishers were Muslims except one respondent in RB which might be due to the $99 \%$ population is muslims, which was quite different with the results of Karim (1994) and Rejwan (2012). There was no significant differences $(\mathrm{P}>0.05)$ in marital status of fishers among location, years and well-being. All the household head were married except $2 \%$ from RB-1 in marginal category and $4 \%$ betteroff from BB-1 but $1 \%$ marginals each from BB-1 and BB-2. The religious and marital status was not affected by the establishment of sanctuary.

In the present study, educational qualification of the fisher's HHH was very poor where the highest degree was upto JSC and majority (71.74\%) of fishers were able to sign only in RB. The capability of sign in RB was increased (71.62\% to $78.38 \%$ ) by the motivation and acitivities by DoF under GPFDP (Greater Pabna Fisheries Development Project). Tanjeena et al. (2006) found the majority of the fishers were able to sign only which was similar to the present study however, the present result was not similar to the findings of Rejwan et al. (2012) and Mahbubur (2001). On the other hand, frequency of dropout children was decreased in RB (41.18\%) and increased in BB $(24.49 \%)$ which might be due the motivation activities arranged by fisheries office staffs and also might be due to up-gradation of their economic status and well-being.

The main occupation was fishing in RB which was similar to the work of Rejwan (2012) and Dev (2011). There was no change in main occupation in RB whereas in BB decreased $14.86 \%$ who were migrated to another IGA. So the fishing was then changed into secondary occupation. Secondary occupation was positively changed side by side into business (1.27\%) for RB of better-off category. So it might be concluded that the changes in occupation was affected by the establishment of sanctuary.

The income from all the sources except labour and others was more or less increased in case of RB but decreased in BB whereas in BB income from others sources was about to same as before except agriculture and labour. Total income was increased $13.58 \%$ in $\mathrm{RB}$ and decreased $4.77 \%$ in $\mathrm{BB}$ which might be due to establishment of the fish sanctuary in RB. Fishing income of the present study area was highest $64.89 \%$ and $43.58 \%$ of total income in $\mathrm{RB}$ and $\mathrm{BB}$, respectively which is supported with small variation by the findings of Karim (2006). The majority of HHH's income was $>500 \leq 800$ US\$. It was revealed from the present study that the positive trends were observed in marginal and better-off fishers whereas vice versa was found in BB. The income from fishing was higher from in the present study than the findings of Karim (2006), DANIDA (2004) and CNRS (2000). Although the result of present study was far difference from the above researchers however it was somewhat relevant to FAP-16 (1994). On the other hand, vice versa was occurred in case of BB. However, 
in case of marginal category the average income was increased in RB and decreased in BB. The upliftment and changes in income were might be due to the establishment of fish sanctuary in RB.

Per capita fish consumption of the fishers of the study area was higher than that of BB. Fish intake by the fishers of RB-2 was more or less similar to national fish intake rate (DoF, 2014). The total amount of fish consumed by the households of RB was higher. BB households purchased more fish from the market and wild sources than RB households which was closely related to the findings of Karim (2006) and Thompson et al. (2005). Overall better-off households' consumption (amount and frequency) was found to be higher than marginal and poor in the present study. It might be concluded that the fish intake was increased in RB due to the availability of fishes which was caused the establishment of fish sanctuary.

The Fishermen were classified into three groups according to natural assets $(\leq 20,>20 \leq 50,>50$ decimal). Majority of HH's land property was $\leq 20$ decimal ( $83 \%$ in RB and $54 \%$ in BB). Positive change was found in $\mathrm{RB}$ for $\leq 20$ category. There were no significant variation in $(\mathrm{P}>0.05) \mathrm{HH}$ frequency by land properties, wellbeing, sites and years. Land holdings were a critical requirement for livelihoods of any households and play a significant role in the socio-economic status of people especially in Bangladesh (Khan, 2004). In the present study, it was found that some HHH have no cultivable land and depended on a small piece of homestead land for housing, food and income. The average land holdings did not vary significantly $(\mathrm{P}>0.05)$ between the sites and years which was supported by the findings of Karim (2006). There was no changes in own land and lease land in BB. However, average lease land was increases $35.29 \%$ in RB which might be due to the establishment of fish sanctuary.

\section{Conclusions}

There are a series of small beel under the Chalan beel which is quite different from biodiversity, water depth, hydrography, physico-chemical characteristics and biological conditions. A large no. of fishermen depends on those beel for their sustainable livelihoods. Fishers are able to gain physical assets, human assets, financial assets as well as natural and social assets through sustainable fishing from Chalan beel due to establishment of fish sanctuary and management it through legal and other effective means.

\section{Acknowledgements}

The authors are grateful to Ministry of Fisheries and Livestock, Government of the Peoples' Republic of Bangladesh for financial support to carry out the study.

\section{Conflict of interest}

None to declare.

\section{References}

Ali M, SS Liaquat, SA Ahmed, PJ Dixon, AS Halls, PM Thompson and P Sultana, 2003. Understanding Livelihoods Dependent on Inland Fisheries in Bangladesh and Southeast Asia, Bangladesh Country Status Report, (DFID/FMSP Project R8118), World Fish Center.

Bashar MA, 1995. Structure of Baculiar haor, Itna, Kishoregonj. MS Thesis, Department of Fisheries Management, Bangladesh Agricultural University, Mymensingh.

Carney D, 1998. Sustainable rural livelihoods. What contribution can we make? Papers presented at the DFID Natural Resources Advisers' Conference, July 1998.

CNRS, 2000. RRA report on Hail Haor site and Turag Bangsi site, MACH Project, Bangladesh.

DANIDA, 2004. Mymensingh Aquaculture Extension Component. Impact evaluation study. GoB Danida Agricultural Sector Programme Support (ASPS) fishery programme. 82 Gulshan, Dhaka, Supported by Royal Danish Embassy, Danish International Development Assiantance, Dhaka Bangladesh. Submitted by Winrock International.

Dev BK, 2011. Co-management participation, livelihood, and status among fishers in Baikka beel, Bangladesh. Rural livelihoods and protected landscapes: co-management in the wetlands and forests of Bangladesh, IPAC Project, Department of Forests, Environment and Fisheries, Dhaka. pp. 66-84.

DFID, 1999. Sustainable Livelihoods and Poverty Elimination: Background Briefing. November 1999 (www.ids.ac.uk/livelihoods.html).

DoF, (Department of Fisheries) 2014. Fish week Compendium. Department of Fisheries, Ministry of Fisheries and Livestock, Dhaka, Bangladesh. pp. 120. 
FAP-16, 1994. Main volume FAP-16 Fisheries studies and pilot project, final report, Government of Bangladesh Flood Action Plan Ministry of Irrigation, Water Development and Flood control, Government of Bangladesh, Dhaka.

Field A, 2005. Discovering Statistics using SPSS. 2nd edn, 779 London. SAGE Publications.

Gay LR, 1976. Educational research: competencies for analysis and application. Columbus, Ohio: Charles E. Merrill Publishing Company.

Haque MM, 2007. Decentralized Fish Seed Networks in Northwest Bangladesh: Impacts on Rural Livelihoods. PhD Thesis. Aquaculture systems and Development Group, Institute of Aquaculture, University of Stirling, Scotland, UK, 2007.

Islam KMM, 2012. Study on the socio-economic conditions of the Haor fishermen under Kishoregonj District, A thesis submitted to the Department of Aquaculture, Faculty of Fisheries, Bangladesh Agricultural University, Mymensingh, in partial fulfillment of the requirements for the degree of Masters of Science (MS) in Aquaculture.

Karim M, 2006. The livelihood impacts of fishponds integrated within farming systems in Mymensingh District, Bangladesh. A thesis submitted for the degree of Doctor of Philosophy by Aquaculture Systems Group, Institute of Aquaculture University of Stirling, Scotland, UK.

Karim MS, 2003. Causes of fisheries resources reduction in Chalan beel. Fish Fortnight Compendium (Matshya Pakkha Songkolon), Department of Fisheries, Ministry of Fisheries and Livestock, Bangladesh. pp. 95-96.

Khan MH, 2004. Power, Property Rights and the Issue of Land Reform: A General Case Illustrated with Reference to Bangladesh. J. Agra. Chan., 4: 73-106.

Mahabubur MR, 2001. Study on the fisheries and socio-economic condition of the fishermen in the Baculiar Haor, Itna, Kishoregonj, MS Thesis, Department of Fisheries Management, BAU, Mymensingh. pp. 62.

Miles J and M Shevlin, 2001. Applying regression and correlation: a guide for students and researchers. London: Sage.

Rejwan KM, KM Adhikary, MB Hossain and MH Minar, 2012. Livelihood Status of Fishermen of the Old Brahmaputra River, Bangladesh. Department of Fisheries Management, BAU, Mymensingh-2202, Bangladesh. J. Wor. Appl. Sci., 16: 869-873.

Sayeed MA, 2010. Fish Biodiversity in the Chalan beel, A Depression in North West Bangladesh. A Ph.D. Dissertation, Submitted to the Bangladesh Agricultural University, Mymensingh, Department of Fisheries Biology and Genetics.

Scoones I, 1998. Sustainable Rural Livelihoods. A framework for analysis. IDS, Working Paper 72, IDS, Brighton, UK, June 1998.

Shamima SH, 2000: Socio-economic condition of fishing community: Gallamary fish market Khulna. B.Sc. Thesis. Fisheries and Marine Resource Technology Discipline, Khulna University, Khulna, pp.11-44.

Snedecor J and WG Cochran 1989. Statistical Methods. Eighth edn, USA: Lowa State University Press.

Tanjeena Z, MAS Jewel and AS Bhuiyan 2006. Present status of pond fishery resources and livelihood of the fish farmers of Mohanpur Upazila in Rajshahi District, Department of Fisheries, University of Rajshahi, Bangladesh. J. Zool., 25: 31-35.

Thompson PM, P Sultana and AKMF Khan 2005. Aquaculture extension impacts in Bangladesh: a case study from Kapasia, Gazipur, World Fish Center contribution no. 1717. Penang, Malaysia. 